Subscriber access provided by Caltech Library

\title{
Communication
}

\section{Mechanochemical Regulation of a Photochemical Reaction}

Xiaoran Hu, Molly McFadden, Ross Barber, and Maxwell J. Robb

J. Am. Chem. Soc., Just Accepted Manuscript • Publication Date (Web): 17 Oct 2018

Downloaded from http://pubs.acs.org on October 17, 2018

\section{Just Accepted}

"Just Accepted" manuscripts have been peer-reviewed and accepted for publication. They are posted online prior to technical editing, formatting for publication and author proofing. The American Chemical Society provides "Just Accepted" as a service to the research community to expedite the dissemination of scientific material as soon as possible after acceptance. "Just Accepted" manuscripts appear in full in PDF format accompanied by an HTML abstract. "Just Accepted" manuscripts have been fully peer reviewed, but should not be considered the official version of record. They are citable by the Digital Object Identifier (DOI®). "Just Accepted" is an optional service offered to authors. Therefore, the "Just Accepted" Web site may not include all articles that will be published in the journal. After a manuscript is technically edited and formatted, it will be removed from the "Just Accepted" Web site and published as an ASAP article. Note that technical editing may introduce minor changes to the manuscript text and/or graphics which could affect content, and all legal disclaimers and ethical guidelines that apply to the journal pertain. ACS cannot be held responsible for errors or consequences arising from the use of information contained in these "Just Accepted" manuscripts. 
Polymer mechanochemistry is an emerging genre of research that investigates the use of mechanical force to promote selective chemical transformations. ${ }^{1}$ Polymer chains transduce an externally applied mechanical stress to a particular covalent bond in mechanochemically active molecules called mechanophores, resulting in a specific chemical reaction. ${ }^{2}$ Research has showcased exciting and unique capabilities of polymer mechanochemistry, contributing to new fundamental understanding of molecular reactivity and creating myriad opportunities for application. For instance, mechanical force has been shown to bias reaction pathways, facilitating formally symmetry-forbidden pericyclic reactions. ${ }^{3}$ Mechanophores have also been designed to produce color changes ${ }^{4}$ and chemiluminescence ${ }^{5}$ for stress-sensing applications, generate reactive functional groups for self-healing materials, ${ }^{6}$ release small molecules, ${ }^{7}$ and produce changes in electrical conductivity. ${ }^{8}$ Despite advance-

\begin{abstract}
We introduce the concept of mechanochemicallygated photoswitching. Mechanical regulation of a photochemical
reaction is exemplified using a newly designed mechanophore based on a cyclopentadiene-maleimide Diels-Alder adduct. Ultrasound-induced mechanical activation of the photochemically inert via a retro $[4+2]$ cycloaddition reaction that photoisomerizes between colorless and colored states upon exposure to UV and visible cyclopentadiene-maleimide adduct and confirm the mechanical origin of the "unlocked" photochromic reactivity. This technology ing, enabling the mechanical history of polymeric materials to be recorded and read on-demand.
\end{abstract}

\section{Scheme 1. Mechanochemically-Gated Photoswitching Using a Cyclopentadiene-Maleimide Mechanophore.}

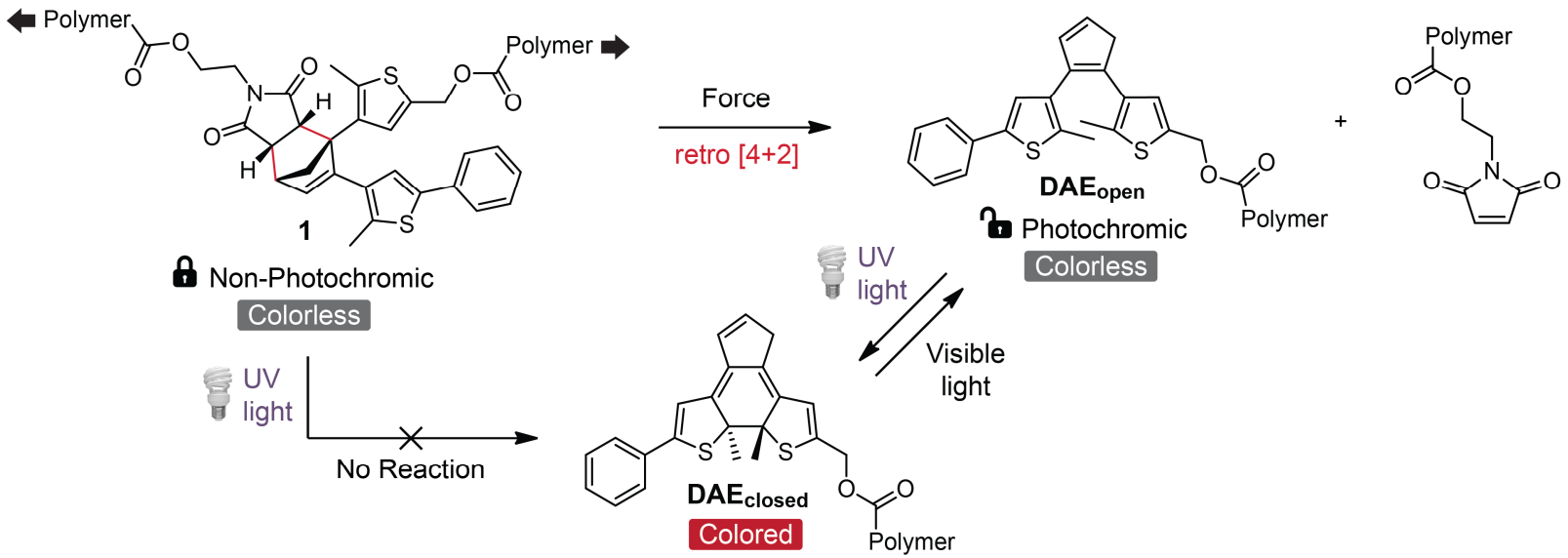

ACS Paragon Plus Environment ments in mechanophore development, expanding the existing repertoire of mechanochemical function will enable novel applications in organic materials.

An undeveloped yet potentially transformative application of polymer mechanochemistry is the use of mechanical force to regulate a secondary chemical transformation. The concept of gating describes a system in which a desired chemical reaction occurs only if it is preceded by a specific stimulus. In 2016, Craig and Boulatov reported the only example of a mechanically-gated reaction in which a molecule containing two distinct mechanochemically active groups underwent sequential activation under force (i.e., the second mechanophore unit was gated by the first). ${ }^{9}$ Conventionally, the gating concept has been applied in the context of photoswitching, where light triggers a chemical change in a molecule to reveal a new structure with unique chemical reactivity (termed photogated reactivity), ${ }^{10}$ or in the case of reactivity-gated photoswitching, ${ }^{11}$ a photoswitchable molecule is revealed after a chemical reaction. ${ }^{12}$

Here we introduce the concept of mechanochemically-gated photoswitching. We report a new mechanophore based on a thermally stable cyclopentadiene-maleimide Diels-Alder adduct that undergoes a retro [4+2] cycloaddition reaction under mechanical force to reveal a diarylethene (DAE) photoswitch. DAEs are an important class of photochromic compounds that undergo $6 \pi$ electrocyclic ring-closing reactions with UV light to produce fully conjugated and intensely colored species, while visible light triggers the reverse ring-opening reaction to regenerate the original colorless molecules. ${ }^{13}$ Mechanical regulation of photochemical reactivity is promising for a variety of applications from novel lithographic methods to stress-sensing, enabling the mechanical history of polymeric materials to be permanently recorded and read on-demand. 
Our strategy for achieving mechanochemically-gated photoswitching is illustrated in Scheme 1. Diels-Alder adducts of maleimide with furan ${ }^{14}$ and anthracene ${ }^{15}$ are well-known mechanophores that undergo retro $[4+2]$ cycloaddition reactions under mechanical force. Accordingly, mechanical activation of cyclopentadiene-maleimide adduct $\mathbf{1}$ is anticipated to generate $\mathbf{D A E}_{\text {open }}$, which photoisomerizes between colorless and colored states upon exposure to UV and visible light. Critically, Diels-Alder adduct 1 is photochemically inert because it does not possess the necessary $6 \pi$ electronic framework for cyclization, which is only revealed after a mechanochemically-induced retro Diels-Alder reaction.

Density functional theory (DFT) calculations using the simple constrained geometries simulate external force (CoGEF) technique ${ }^{16}$ were initially performed at the B3LYP/6-31G* level theory to evaluate the mechanochemical activity of cyclopentadiene-maleimide adduct 1 (Figure 1). Starting from the equilibrium geometry of a truncated structure with terminal acetyl groups, the constrained distance between methyl carbon atoms was increased in increments of $0.05 \AA$ and the energy of the molecule was minimized at each step. The computational results indicate that mechanical elongation of the cyclopentadiene-maleimide adduct induces a retro Diels-Alder reaction to generate the expected cyclopentadiene-based DAE and maleimide fragments. The reaction occurs with an estimated rupture force of $4.6 \mathrm{nN}$, which is comparable to rupture forces calculated with the CoGEF method for many other putative mechanophores including furan-maleimide Diels-Alder adducts. ${ }^{14 a}$ It is important to note that forces calculated with the CoGEF method are typically overestimated compared to experiments $;{ }^{17}$ nevertheless, they provide a useful framework for evaluating relative mechanochemical activity.

We next set out to synthesize the cyclopentadiene-maleimide adduct and incorporate it into a polymer to investigate its mechanochemical properties experimentally (Scheme 2, see the Supporting Information (SI) for details). Polymers containing a chain-centered mechanophore are mechanically activated in solution using ultrasonication, which produces shear forces maximized near the chain midpoint. ${ }^{18}$ Starting from DAE molecule $2,{ }^{19}$ a formylation reaction followed by a two-step reduction and protection sequence afforded 4. Oxidation following Branda's conditions ${ }^{10 a}$ using bro-

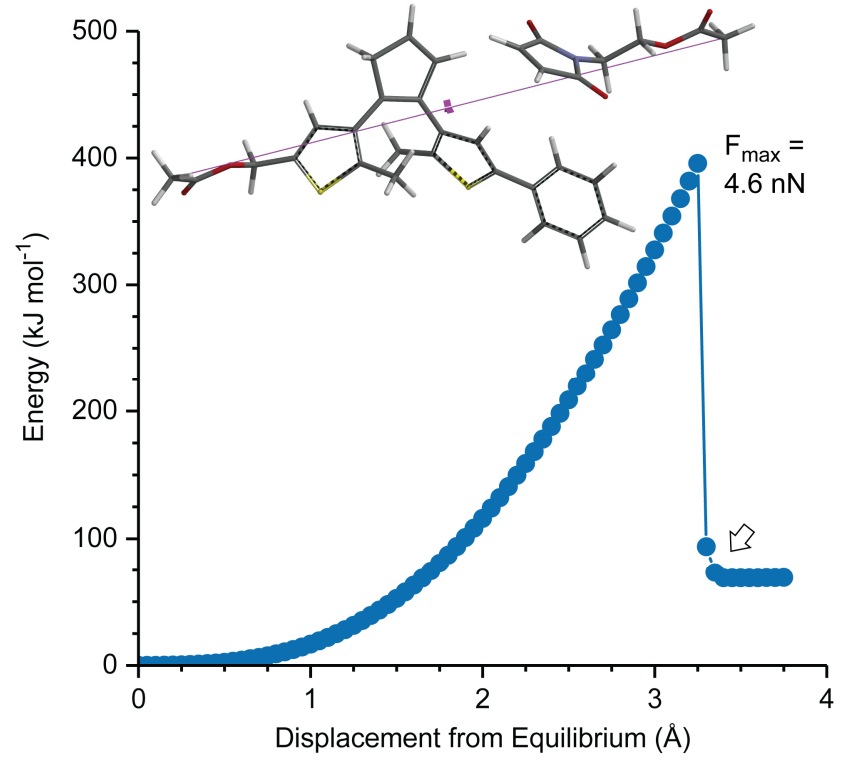

Figure 1. DFT calculations using the constrained geometries simulate external force (CoGEF) method predict the formation of cyclopentadiene-based DAE and maleimide fragments resulting from a retro [4+2] cycloaddition reaction upon mechanical elongation of the Diels-Alder adduct. The calculated structures shown correspond to the data point indicated by the arrow. Calculations were performed at the B3LYP/6-31G* level of theory.

mine in diethyl ether provided a mixture of cyclopentadiene isomers, including 1,2-disubstituted DAE 5. The mixture of isomers was reacted with $\mathrm{N}$-(2-hydroxyethyl)maleimide in dichloromethane at room temperature to provide a separable mixture of isomeric Diels-Alder adducts, including two with the desired norbornene imide architecture as identified by ${ }^{1} \mathrm{H}$ NMR spectroscopy. These two isomers possess a 2,3-diaryl substituted olefin and differ in the regiochemistry of the thienyl substituents, having the hydroxymethyl-substituted thiophene located alpha (proximal) or beta (distal) to the diene/maleimide junction. Stevenson and De Bo

\section{Scheme 2. Synthesis of Poly(Methyl Acrylate) (PMA) Containing a Chain-Centered Cyclopentadiene-Maleimide Adduct and Structure of a Chain-End Functional Control Polymer.}
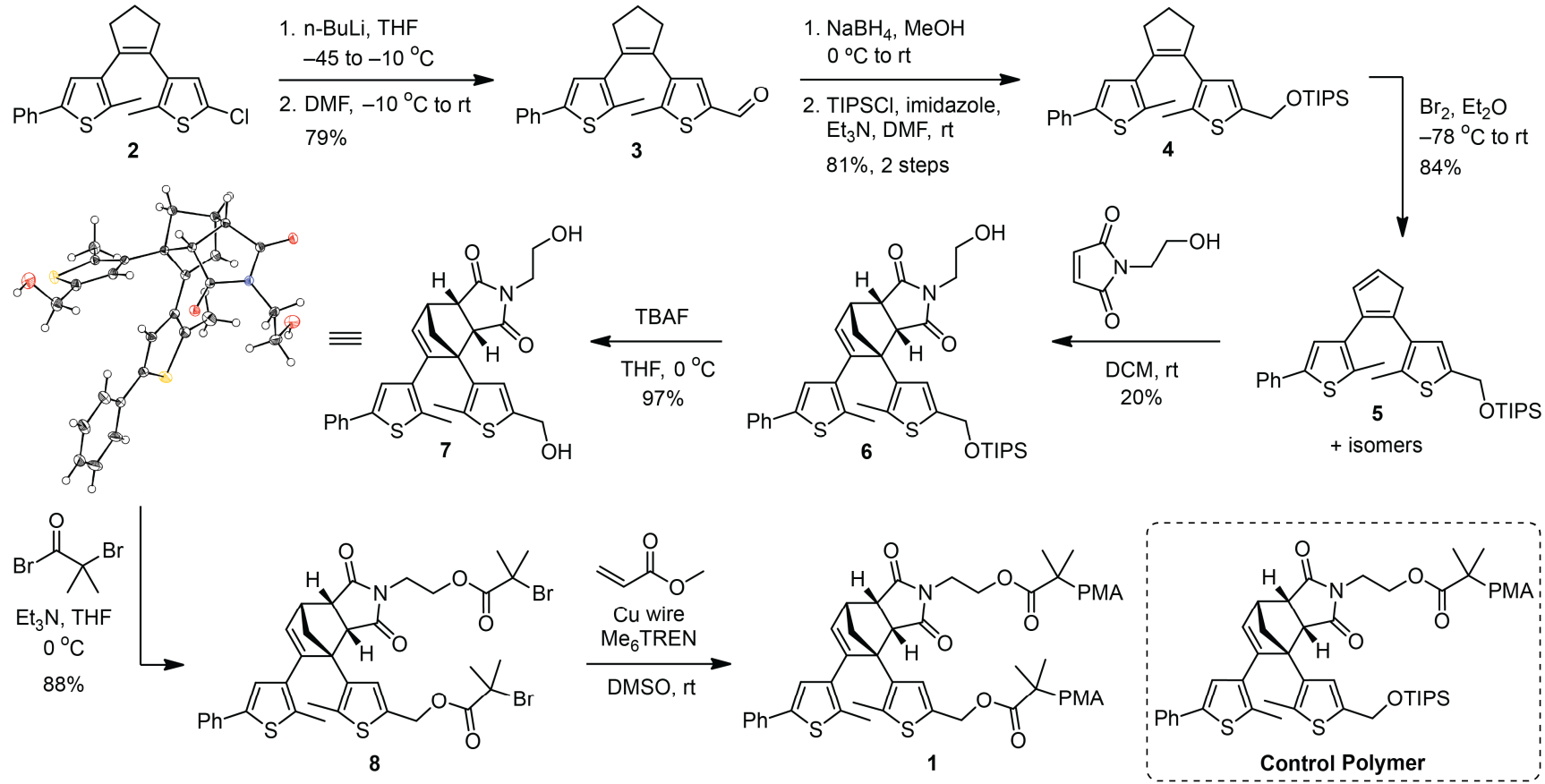
recently reported the enhanced reactivity of analogous furan-maleimide adducts having a proximal pulling geometry. ${ }^{14 a}$ Therefore, we focused our investigation on isomer 7 , which was characterized by single crystal X-ray diffraction to have a proximal geometry and endo configuration after removal of the TIPS protecting group. Esterification with $\alpha$-bromoisobutyryl bromide furnished bifunctional initiator 8 , which was subsequently employed in the controlled radical polymerization of methyl acrylate using $\mathrm{Cu}$ wire/ $\mathrm{Me}_{6} \mathrm{TREN}$ in DMSO to afford poly(methyl acrylate) (PMA) polymer 1 containing the chain-centered cyclopentadiene-maleimide adduct $\left(M_{\mathrm{n}}=\right.$ $90 \mathrm{~kg} / \mathrm{mol} ; Ð=1.09$ ).

Mechanochemical activity of the cyclopentadiene-maleimide Diels-Alder adduct was evaluated using pulsed ultrasonication (1 $\mathrm{s}$ on $/ 2 \mathrm{~s}$ off, $\left.11.0 \mathrm{~W} / \mathrm{cm}^{2}\right)$ in THF at $0{ }^{\circ} \mathrm{C}$. Molecular weights were measured as a function of ultrasonication time by gel permeation chromatography (GPC) monitored with a multi-angle light scattering detector. Polymer 1 exhibited a steady change in $M_{\mathrm{n}}$ over 90 min of sonication time, decreasing from $90 \mathrm{~kg} / \mathrm{mol}\left(M_{\mathrm{i}}\right)$ to 48 $\mathrm{kg} / \mathrm{mol}$ (Figure 2). The GPC chromatograms measured using a re-

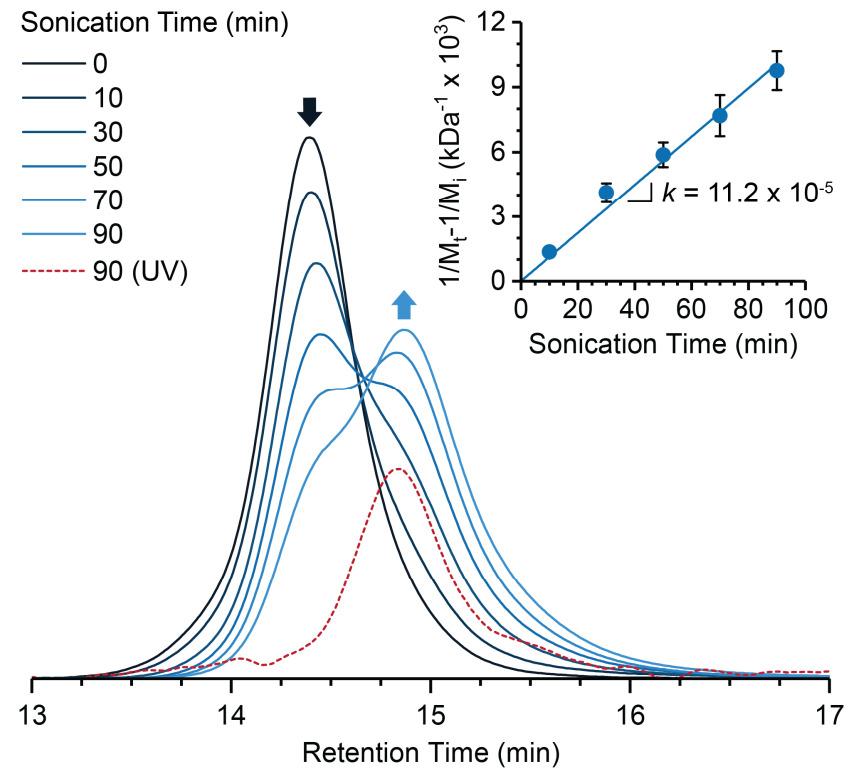

Figure 2. GPC traces (RI) and molecular weight data for polymer 1 as a function of ultrasonication time. Ultrasound-induced mechanochemical activation causes chain scission near the polymer midpoint, resulting in attenuation of the initial polymer peak and an increase in a new peak at approximately one-half the original $M_{\mathrm{n}}$. A sample subjected to ultrasonication for $90 \mathrm{~min}$ was irradiated with UV light $(\lambda=311 \mathrm{~nm}, 60 \mathrm{~s})$ immediately prior to analysis by GPC using a UV-vis detector monitored at 460-550 nm, demonstrating the generation of a photochromic moiety covalently bound to the polymer fragment (red dashed trace). The inset shows the measured rate constant for polymer chain scission from four replicate experiments. Error bars represent standard deviation.

fractive index (RI) detector clearly illustrate the attenuation of the initial polymer peak $\left(M_{\mathrm{p}}=92 \mathrm{~kg} / \mathrm{mol}\right)$ with the generation of a new, well-defined peak $\left(M_{\mathrm{p}}=51 \mathrm{~kg} / \mathrm{mol}\right)$ at approximately one-half the original molecular weight as expected for site-selective cleavage of the cyclopentadiene-maleimide adduct located near the center of the polymer chains. The average rate constant and standard deviation for chain scission, $k^{\prime}$, was measured to be $(11.2 \pm 1.1) \times 10^{-5}$ $\mathrm{kDa}^{-1} \mathrm{~min}^{-1}$ from four replicate experiments (see the SI for details). Additional GPC measurements using a UV-vis detector provided insight into the photochemical properties of the polymer after ultrasonication. Irradiation of the polymer solutions with UV light $(\lambda$ $=311 \mathrm{~nm}$ ) immediately prior to GPC analysis revealed a new peak

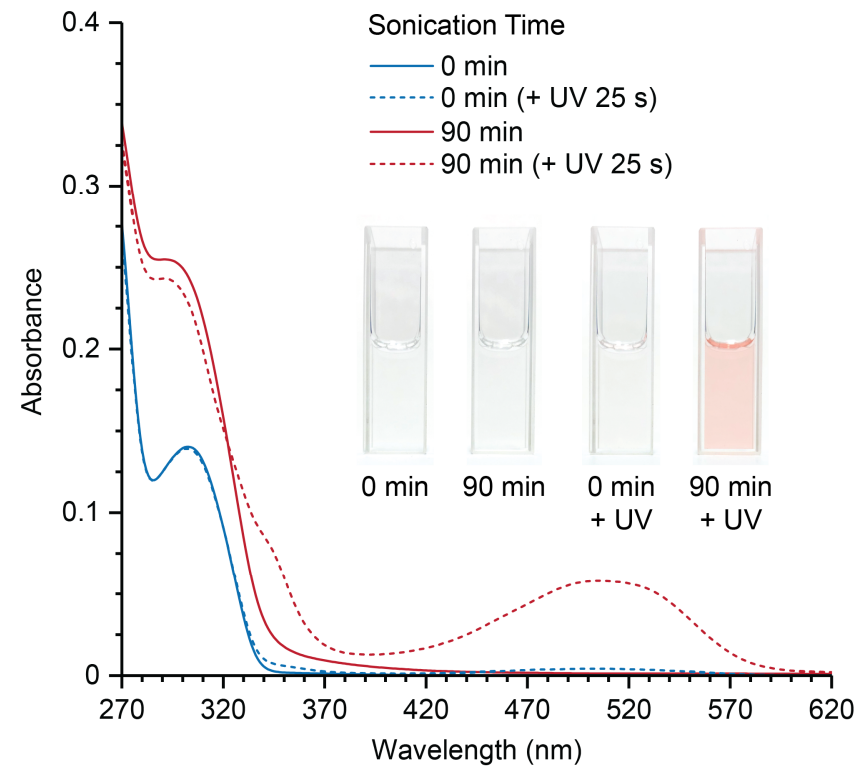

Figure 3. UV-vis absorption spectra of polymer 1 before and after ultrasonication and UV irradiation demonstrating mechanochemically-gated photoswitching. Ultrasound-induced mechanical force reveals a latent diarylethene photoswitch that isomerizes under UV light $(\lambda=311 \mathrm{~nm}, 25 \mathrm{~s})$ to generate a colored species with an absorption maximum at $505 \mathrm{~nm}$. Photographs of THF solutions of polymer 1 illustrate the visual change in color of the mechanochemically activated material, transforming from colorless to red upon exposure to UV irradiation. The solution of polymer 1 remains colorless under UV light prior to mechanical activation.

monitored at 460-550 nm (vide infra). Importantly, this peak coincides with the low molecular weight fragment peak in the refractive index traces, indicating that a polymer-bound photochromic moiety is produced upon chain scission (red dashed trace in Figure 2).

The photochemical changes that accompany mechanochemical chain scission of polymer $\mathbf{1}$ were further investigated by UV-vis spectroscopy (Figure 3 and Figure S1). Aliquots were removed from the polymer solution during ultrasonication at $0,10,30,50$, 70 , and $90 \mathrm{~min}$ and the absorption spectrum was measured for each sample. The peak absorbance of the polymer solution increases in the region of $290-310 \mathrm{~nm}$ with increasing ultrasonication time. The solution remained colorless throughout the duration of the ultrasonication treatment. Remarkably, irradiation of the same samples with UV light revealed a new broad peak in the absorption spectra centered at $505 \mathrm{~nm}$ that increased in optical density with longer ultrasonication times. This new photochromic peak matches the absorption spectrum of the ring-closed species isolated from the mixture of cyclopentadiene isomers containing DAE 5 after UV irradiation (Figure S2, see the SI for details). The spectroscopic changes that accompany the ultrasound-induced mechanical activation of polymer $\mathbf{1}$ are visually reflected in the color of the solutions, transforming from colorless to red upon exposure to UV light. The colored isomer is stable in the dark at ambient temperature with negligible changes observed in the absorption spectrum over $25 \mathrm{~min}$ (Figure S3). Moreover, the photochromic behavior of polymer 1 after mechanical activation was reversible over six cycles with alternating irradiation using UV and visible light (Figure S4).

We note that the solution of polymer 1 prior to ultrasonication displays a very weak photochromic peak in the absorption spectrum after UV irradiation. To further investigate this feature and confirm the mechanical origin of the observed chemical transformations induced by ultrasonication, we prepared an end-functional control polymer containing the cyclopentadiene-maleimide mechanophore at the chain end (see Scheme 2 for structure). The control polymer 
$\left(M_{\mathrm{n}}=93 \mathrm{~kg} / \mathrm{mol} ; \emptyset=1.08\right)$ was synthesized in an analogous manner to polymer 1 starting from TIPS-protected Diels-Alder adduct 6 with a single hydroxyl group (see the SI for details). The control polymer was subjected to ultrasonication under the same conditions as above and analyzed by UV-vis spectroscopy. Interestingly, the same weak photochromic peak was present in the absorption spectrum of the control polymer after exposure to UV light prior to ultrasonication; however, in direct contrast to polymer 1 containing the chain-centered cyclopentadiene-maleimide adduct, no changes in the photochromic properties of the control polymer were observed after $90 \mathrm{~min}$ of ultrasonication (Figure S5). These results indicate that mechanical force is responsible for the changes in photochemical behavior observed for polymer $\mathbf{1}$ and preclude alternative reaction pathways due to thermal or photochemical activation of the cyclopentadiene-maleimide mechanophore during ultrasonication. Additionally, heating a solution of Diels-Alder adduct 7 in toluene- $d 8$ at $90{ }^{\circ} \mathrm{C}$ for 3 hours resulted in no changes to the UVvis or ${ }^{1} \mathrm{H}$ NMR spectra (Figure S6 and Figure S7, respectively), confirming the thermal stability of the cyclopentadiene-maleimide mechanophore.

In summary, we have introduced the concept of mechanochemically-gated photoswitching. Mechanochemical activation of a newly designed cyclopentadiene-maleimide mechanophore reveals a latent photochromic diarylethene (DAE) molecule in polymers via a retro Diels-Alder reaction. The mechanochemically generated DAE photoswitch undergoes a reversible photoisomerization reaction, switching between colorless and colored states upon exposure to UV and visible light. Control experiments confirm that mechanical force is responsible for "unlocking" the photochromic properties of the cyclopentadiene-maleimide mechanophore. Our laboratory is currently investigating this technology as a new platform for stress sensing, encryption, and patterning applications in polymeric materials.

\section{ASSOCIATED CONTENT}

\section{Supporting Information}

The Supporting Information is available free of charge on the ACS Publications website.

Crystallographic data for 7 (CIF).

Experimental details, synthetic procedures, GPC chromatograms, UV-vis and NMR spectra (PDF).

\section{AUTHOR INFORMATION}

\section{Corresponding Author}

mrobb@caltech.edu

\section{Notes}

The authors declare no competing financial interests.

\section{ACKNOWLEDGMENT}

We thank Dr. Scott Virgil for assistance with chromatography and helpful discussions and the Caltech Center for Catalysis and Chemical Synthesis for access to equipment. We also thank Larry Henling for assistance with X-ray crystallography. Financial support from Caltech and the Dow Next Generation Educator Fund is gratefully acknowledged.

\section{REFERENCES}

(1) (a) Beyer, M. K.; Clausen-Schaumann, H. Chem. Rev. 2005, 105, 2921-2948. (b) Caruso, M. M.; Davis, D. A.; Shen, Q.; Odom, S. A.; Sottos, N. R.; White, S. R.; Moore, J. S. Chem. Rev. 2009, 109, 5755-5798.

(2) Li, J.; Nagamani, C.; Moore, J. S. Acc. Chem. Res. 2015, 48, 21812190.

(3) (a) Hickenboth, C. R.; Moore, J. S.; White, S. R.; Sottos, N. R.; Baudry, J.; Wilson, S. R. Nature 2007, 446, 423-427. (b) Wang, J.; Kouznetsova, T. B.; Niu, Z.; Ong, M. T.; Klukovich, H. M.; Rheingold, A. L.; Martinez, T. J.; Craig, S. L. Nat. Chem. 2015, 7, 323-327. (c) Wollenhaupt, M.; Krupička, M.; Marx, D. ChemPhysChem 2015, 16, 1593-1597.

(4) (a) Davis, D. A.; Hamilton, A.; Yang, J.; Cremar, L. D.; Van Gough, D.; Potisek, S. L.; Ong, M. T.; Braun, P. V.; Martínez, T. J.; White, S. R.; Moore, J. S.; Sottos, N. R. Nature 2009, 459, 68-72. (b) Gossweiler, G. R.; Hewage, G. B.; Soriano, G.; Wang, Q.; Welshofer, G. W.; Zhao, X.; Craig, S. L. ACS Macro Lett. 2014, 3, 216-219. (c) Robb, M. J.; Kim, T. A.; Halmes, A. J.; White, S. R.; Sottos, N. R.; Moore, J. S. J. Am. Chem. Soc. 2016, 138, 12328-12331. (d) Peterson, G. I.; Larsen, M. B.; Ganter, M. A.; Storti, D. W.; Boydston, A. J. ACS Appl. Mater. Interfaces 2015, 7, 577583. (e) Imato, K.; Irie, A.; Kosuge, T.; Ohishi, T.; Nishihara, M.; Takahara, A.; Otsuka, H. Angew. Chem. Int. Ed. 2015, 54, 6168-6172.

(5) Chen, Y.; Spiering, A. J. H.; Karthikeyan, S.; Peters, G. W. M.; Meijer, E. W.; Sijbesma, R. P. Nat. Chem. 2012, 4, 559-562.

(6) (a) Ramirez, A. L. B.; Kean, Z. S.; Orlicki, J. A.; Champhekar, M.; Elsakr, S. M.; Krause, W. E.; Craig, S. L. Nat. Chem. 2013, 5, 757-761. (b) Robb, M. J.; Moore, J. S. J. Am. Chem. Soc. 2015, 137, 10946-10949. (c) Zhang, H.; Gao, F.; Cao, X.; Li, Y.; Xu, Y.; Weng, W.; Boulatov, R. Angew. Chem. Int. Ed. 2016, 55, 3040-3044. (d) Wang, J.; Piskun, I.; Craig, S. L. ACS Macro Lett. 2015, 834-837.

(7) (a) Larsen, M. B.; Boydston, A. J. J. Am. Chem. Soc. 2013, 135, 8189-8192. (b) Diesendruck, C. E.; Steinberg, B. D.; Sugai, N.; Silberstein, M. N.; Sottos, N. R.; White, S. R.; Braun, P. V.; Moore, J. S. J. Am. Chem. Soc. 2012, 134, 12446-12449.

(8) Chen, Z.; Mercer, J. A. M.; Zhu, X.; Romaniuk, J. A. H.; Pfattner, R.; Cegelski, L.; Martinez, T. J.; Burns, N. Z.; Xia, Y. Science 2017, 357, 475-479.

(9) Wang, J.; Kouznetsova, T. B.; Boulatov, R.; Craig, S. L. Nat. Commun. 2016, 7, 13433.

(10) (a) Lemieux, V.; Gauthier, S.; Branda, N. R. Angew. Chem. Int. Ed. 2006, 45, 6820-6824. (b) Göstl, R.; Hecht, S. Angew. Chem. Int. Ed. 2014 53, 8784-8787. (c) Photochemical modulation of the mechanochemical reactivity of a furan-maleimide Diels-Alder adduct was recently reported: Kida, J.; Imato, K.; Goseki, R.; Aoki, D.; Morimoto, M.; Otsuka, H. Nat. Commun. 2018, 9, 3504.

(11) Yokoyama, Y.; Yamane, T.; Kurita, Y. J. Chem. Soc., Chem. Commun. 1991, 1722-1724.

(12) (a) Lemieux, V.; Branda, N. R. Org. Lett. 2005, 7, 2969-2972. (b) Kühni, J.; Belser, P. Org. Lett. 2007, 9, 1915-1918. (c) Ohsumi, M.; Fukaminato, T.; Irie, M. Chem. Commun. 2005, 3921-3923. (d) Kawai, S. H.; Gilat, S. L.; Lehn, J.-M. Eur. J. Org. Chem. 1999, 1999, 2359-2366. (e) Irie, M.; Miyatake, O.; Uchida, K. J. Am. Chem. Soc. 1992, 114, 87158716.

(13) Irie, M.; Fukaminato, T.; Matsuda, K.; Kobatake, S. Chem. Rev. 2014, 114, 12174-12277.

(14) (a) Stevenson, R.; De Bo, G. J. Am. Chem. Soc. 2017, 139, 16768 16771. (b) Duan, H.-Y.; Wang, Y.-X.; Wang, L.-J.; Min, Y.-Q.; Zhang, X.H.; Du, B.-Y. Macromolecules 2017, 50, 1353-1361.

(15) (a) Li, J.; Shiraki, T.; Hu, B.; Wright, R. A. E.; Zhao, B.; Moore, J. S. J. Am. Chem. Soc. 2014, 136, 15925-15928. (b) Sung, J.; Robb, M. J.; White, S. R.; Moore, J. S.; Sottos, N. R. J. Am. Chem. Soc. 2018, 140, 5000 5003. (c) Konda, S. S. M.; Brantley, J. N.; Varghese, B. T.; Wiggins, K. M.; Bielawski, C. W.; Makarov, D. E. J. Am. Chem. Soc. 2013, 135, 1272212729.

(16) (a) Beyer, M. K. J. Chem. Phys. 2000, 112, 7307-7312. (b) Kryger, M. J.; Munaretto, A. M.; Moore, J. S. J. Am. Chem. Soc. 2011, 133, 18992 18998.

(17) Stauch, T.; Dreuw, A. Chem. Rev. 2016, 116, 14137-14180.

(18) Berkowski, K. L.; Potisek, S. L.; Hickenboth, C. R.; Moore, J. S. Macromolecules 2005, 38, 8975-8978.

(19) Kobatake, S.; Terakawa, Y. Chem. Commun. 2007, 1698-1700. 
Insert Table of Contents artwork here

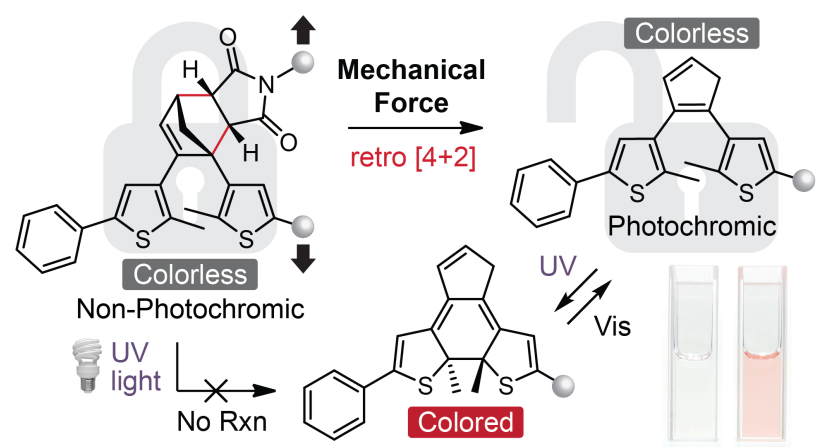

